\title{
Economic Analysis of Central Bank Interest Rate Expectations and Impacts on the Real Estate Market Forecast
}

\author{
Hongen $\mathrm{Li}^{1, \mathrm{a}^{*}}$ and Shuxian Deng ${ }^{1,2, \mathrm{~b}}$ \\ ${ }^{1}$ Department of Basic Courses, Zhengzhou University of Industrial Technology, Xinzheng, China \\ ${ }^{2}$ College of Science, Henan University of Engineering, Zhengzhou, China \\ a857931663@qq.com, bdshuxian@163.com \\ *The corresponding author
}

Keywords: Interest; Real estate; Forecast; Analysis

\begin{abstract}
This paper analyzes the February 3rd People's Bank of Chinese raised the reverse repo rate and standing loan facilities (SLF) interest rate move, combined with the previous soon has raised the medium-term lending facility (MLF) rate measures, pointed out that the interest rate increase after another, attention will lead the market. Forecast the central bank chooses in the money market operations to raise interest rates in 2017 China monetary policy at the same time analysis and, and for the 2017 fiscal year Chinese economic structural adjustment, promote the effect of supply side reforms, especially the impact on the development of the real estate market in 2017 China.
\end{abstract}

\section{Introduction}

In recent years, the central bank's monetary policy, more and more concentrated in the inter-bank money market. In this market, the central bank through a variety of ways to provide funds to the liquidity needs of financial institutions to obtain funds, here the operation rate is the cost of financial institutions. The central bank repurchase is on every working day of the open market operation, the the purpose is to give the financial market to send a clear signal to influence the direction of development and expectations of the financial market, and we are familiar with SLF and MLF on the central bank's financial institutions to carry out the "one to one" operation, to provide this kind of financial maturity from overnight to 1 years [1,2].

February 3rd is the end of the Lunar New Year holiday after the first working day, the people's Bank of Chinese raised the reverse repo rate and convenient standing lending (SLF) interest rate. The Central Bank of the 28 day, 14 day and 7 day repurchase operation successful rate was compared with a slight increase of 10 basis points ( 1 basis points to 1/10000) on the same day; as the interest rate corridor ceiling SLF overnight, 7 days, 1 month interest rates were raised by 35,10,10 basis points; and shortly after January 24th, that is the Spring Festival holiday, the central bank has raised the medium-term lending facility (MLF) rate of.6 months, 1 year MLF rate than the last operation increased by 10 basis points.

In 2016 Chinese economy faces many uncertain factors, the situation is very complex under the background of the interest rate increase after another, will cause the market attention. Why central banks choose to operate in the money market interest rates rise? This indicates to China monetary policy in 2017 how to Chinese economy? What impact will have? China become a pillar of economic development of the real estate industry will produce what effect?

Generally, this is actually a disguised interest and intends to tighten liquidity. This phenomenon is brought directly after the Spring Festival on the first day of trading the stock market did not usher in a good start, the official interpretation of the central bank to move the return to a prudent monetary policy is neutral, its purpose is to control the financial risks and to leverage due to the central bank. Has taken up money market interest rate, the actual effect from the perspective of economics is to moderate suppression of the irrational behavior of financial institutions and the appropriate cooling on asset prices[3]. 


\section{The Increase in the Operating Rate of the Money Market Interest Rates to Enhance the Community's Interest Rate Expectations, But It Does not Mean That Interest Rates}

It has always been the subject of attention at home and abroad to the country's monetary policy. Especially in today's international economic downturn, the financial situation is grim, the domestic economic structure unreasonable, the enormous downward pressure, the financial situation is severe and complicated situation. But we should note that the central bank "hit" the object is not directly manipulate the public and the deposit and loan business entities, but manipulation exists between banks and other financial institutions in the currency market[4,5].

This is the charge for the central bank to raise interest rates when the financial institutions to provide funds, but not raised the benchmark deposit and loan interest rates, that is not a direct intervention on the deposit and loan interest rates. We know that the interest rate changes in the money market, has a very close relationship with the change of deposit and loan interest rates, but both of them are not synchronous, also do not have the necessary connection, sometimes the money market interest rate changes by financial institutions responsible for digestion, does not affect the changes in interest rates, but more cases will gradually by conduction, deposit and loan interest rates also make every move change. So this adjustment does not mean that the deposit and loan interest rates upward, is to raise interest rates, but this will strengthen the social expectations of deposit and loan interest rates to rise.

The development of the financial market in a period, from short-term interest rates to medium-term interest rates from the open market operation to the "one to one" operation, the money market interest rate has indeed showed a gradually upward trend. The central bank raised interest rates on money market operations initiatives, the flow, is based on the domestic and international economic development the situation and to take the Suihangjiushi move. In 2016, China's monetary policy, the central rate of monetary market is gradually rising, from the development of international money market, the interest rate is also up in general, in this case, if the Central Bank of the operation of the money market interest rates are not adjusted to keep the previous operating rate the same, the relevant financial institution is prone to speculation to borrow money from the central bank cash spreads.

The economic law tells us that changes in the money market, and will not quickly, directly transmitted to the level of the enterprise and the people, and there will be a delay, buffer, melting and digestion process. The development trend of change but people can be manipulated through the money market interest rate to expected financial market, forecast the future of economic policy in advance. Adjust the development ideas and Strategies of enterprise from the perspective of economic development, in order to conform to the financial requirements. From the personal perspective, people can also adjust their investment through the forecast of financial policy, financial and consumer strategy. Different from the western developed country situation the China, financial institutions rely more on deposits, Chinese entities rely more on bank loans, Chinese of the real estate industry in the national economy and status in the development of an increasingly large proportion of enterprises and the old People are more engaged in the real estate market, resulting in financial leverage is more and more strong, more and more risks. So the change of the money market interest rates will inevitably lead to expectations of future economic development policy changes. But it does not mean that will completely and quickly transmitted to the deposit interest rate, the central bank raised the money market the operation rate, only strengthen the social regulation of deposit and loan expectations, of course, this expectation will affect the economic society for a period of time for their own future development strategy adjustment[6].

\section{Economic Interpretation about the Central Bank Chose to Raise Interest Rates at This Time}

The central bank in February 3rd this day to select the above action actually indicates that this is a disguised form of interest rate behavior, its purpose is to tighten liquidity, the stock market after the Spring Festival, also let the stock market on the first day of trading have ushered in the opener. The official action interpretation for prudent monetary neutrality the policy objective is to control the financial risk and leverage to take up money market operations due to the interest rate, from a practical point of view can indeed moderate suppression of the irrational behavior of financial institutions and 
asset prices to moderate cooling.

In a period of China's central bank monetary policy on a series of initiatives, we can easily find the move for the central bank to tighten liquidity, in fact has already revealed a clue, but take this action techniques and tools and different from the past, and at the time of implementation are more subtle, released the signal and policy tendency, we need to interpret carefully. For example, early in the fourth quarter of 2016 the central bank has taken a series of measures to tighten liquidity. In the broad credit assessment for the first time the central bank will bank balance sheet financing into the scope of examination, the extent of the financial system to balance sheet risk certain preventive effect, at the same time also has the compression of the liquidity expansion phenomenon of banks.

The central bank has taken these measures, but also through the full range of considerations, through these operations can avoid a great impact on the real economy and bring large fluctuations in asset prices. From the development of domestic and international economic situation in recent years to see, because of the influence of uncertain factors, the international market the economic and financial situation is very complicated. Downtown pressure on the economy, trade protectionism of these very complex situation will force the central bank will in the future implementation of monetary policy very cautious and extremely difficult. Especially in recent years, the RMB exchange rate has been in a strong devaluation expectations, at the same time, the prices of assets and the lack of confidence and the development of the domestic economy is not very clear, whether the recovery is influenced by many uncertain factors. So the financial and economic situation. Monetary policy makers unusually careful and cautious monetary policy[7]. If excessive force can easily cause volatility in asset prices caused by price instability, to the stable exchange rate expectations and will have a tremendous negative impact, it will aggravate the RMB devaluation expectations. Therefore, the central bank adopted a flexible ingenious method to tighten the in this operation, avoid the overall tightening of liquidity, and the fluctuation caused by the panic.

We note that the central bank's actions caused a lot of speculation in the society, analysis and discussion, but this is not the point, for the assets, the price stability and attraction is the most critical, monetary policy can only play a temporary stability, ease and improve the role, that is to say, only is a temporary solution, can not solve the problem in essence. And in order to stabilize the exchange rate issue, the government needs to reform in the future, will be a concrete and detailed blueprint. China economic development target direction through this blueprint can clear the transition period, and the pace of development so as to avoid. The Society of blind panic, make the society have a clear understanding of the future trend of Chinese economic development, have a stable market expectations, we can avoid the blind and swap for capital Blind flight. At the same time, to play the leading role in the stock market financing, one aspect is also very important to improve the RMB asset price attractive, should strive to avoid further expansion of the real estate market bubble. By boosting the stock market confidence, further clear and expand investment and financing channels, can effectively avoid strong expectations the devaluation of the renminbi, so as to avoid further capital flight caused.

From the international perspective, we are faced with external uncertainties are quite complex, the restoration and development of the world economy is still weak, weak external demand, sluggish growth, also dragged down the speed of economic development in China. Especially the new U.S. government came to power, the Sino US relations especially in the economic and trade relations is facing significant challenges, he threatened to Chinese as a currency manipulator before the U.S. government, and to impose high taxes on Chinese exports, which caused the worries of the world, also make China the resumption of economic growth development is facing a severe test. These phenomena show that in 2017 the global economy, international order and financial markets still have to face the turmoil and unrest. Of course, this is a challenge for us, but also an opportunity, whole world is focused on China, China economic development, has become the world's economic development engine China, rising economic status and increasingly integrated into the international economic system, it provides a good opportunity for us to participate in global governance. Although the United States, the global strategic priority between the United States and China, currency wars, trade war is difficult to avoid, but the uncertainty of this opportunity, challenge and test, just as we lead into the global governance. The development of the world economy to provide a perfect chance to warm up.

Of course, in the current situation and environment, to meet this challenge, grasp this opportunity, it 
is not an easy thing[8]. Especially in the exchange rate and asset prices and other difficult issues, which we do need to show great wisdom, play money to non conventional thinking and strategy to deal with them. The traditional mode of capital controls to avoid capital flight, is only a matter of expediency, not a policy, only to the stability of the RMB exchange rate, can effectively reduce capital flight will.

The exchange rate is expected to do everything possible to stabilize the exchange rate, exchange rate expectations are based and stable asset price stability. In order to effectively stabilize asset prices, we must do everything possible for the investment of funds to find a way out. From the current economic situation, capital effective way is in the real estate market, but after the crazy development in recent decades the real estate market, the volume of puffiness is more and more big, apparently not pushed up the real estate market and other markets. For example, the art market, commodity market capacity is relatively limited, cannot be accommodated into the inclusive society capital. Therefore, we can only put their hopes in the stock market and the stock market, because this two of the market volume is relatively large, can accommodate a large number of liquidity ability. Therefore, in 2017 the stock market's rise and fall and rise and fall will directly affect China's economic development. The potential and overall situation, at the same time the 2017 monetary policy determines the trend of the stock market. Therefore, from the perspective of economics, China's monetary policy should be prudent in 2017, not only to avoid overkill, but also avoid the cop-out, that is to say that the return to maintain a neutral state.

\section{The Central Bank's Move Is another Manifestation of a Sound Monetary Policy to Prevent Risk Deleveraging}

From an economic point of view, although the money market interest rates will not directly affect the adjustment of the social economy and other people living in the community, but there is no doubt that this operation has clearly released some policy signals.

From the current economic structure of our country, China's current economic structural contradictions still exist, the distortion of economic structure and the imbalance of this phenomenon has not been significantly improved, in this case if excessive expansion of aggregate demand, will further solidify the structural distortion and imbalance. Originally the society a person with breadth of vision inflation expectations have been heavy-hearted, while a part of the bubble problem in the field of assets has been very obvious even more serious, making the central bank prudent monetary policy has been a severe challenge. With economic globalization this open macro background pattern, we are also faced with the strong contrast rate of hard constraints and asset prices, in this macro, the smooth and effective implementation of prudent monetary policy is very important.

Since 2011, China implemented a prudent monetary policy, the implementation of this policy, from the overall perspective made significant, positive effect. But we should also see that with the ideal goal there is a certain gap. This is mainly due to the greater downward pressure on the economy, a variety of factors and social the economic structure contradiction, at the same time in the real estate market due to financial leverage is more and more strong, the economic phenomenon in China is very complex and difficult, forcing the central bank had to be in a different time, in a prudent monetary policy implementation, adopt loose or tight policy. Therefore in the recent meeting of the central economic work conference proposed especially in 2017 China's monetary policy can be simply summarized as stable neutral, its purpose is to macroscopically further accurate grasp of monetary policy control Effectiveness, intensity and rhythm, to further balance the relationship between a number of goals.

Thus, the central bank's move, the purpose is to transfer a warning signal to the market to prevent the risk of leverage, while taking a smaller increase money market interest rates to shock and impact in the specific operation, by this way can give market participants to set aside more buffer time and the chance to avoid have a greater impact on all sectors of society, the macroeconomic and financial stability.

From the past two years the social and economic environment, the original implementation of the loose monetary policy is not suitable for the current social and economic order, the implementation of continuous interest rates drop quasi economic environment has undergone tremendous changes. The implementation of prudent and slightly tight monetary policy operation is the best suitable for the operation of the current economic environment. From the central bank since last year the first half of a 
series of operations in the money market has been clear and clearly confirms this point[9].

The real estate market long-term crazy expansion, so that the real economy has been greatly compressed and shrinking, social economic structure contradictions resulting in more and more prominent, the asset bubble has been blown up, and this corresponds to the strengthening effect of financial leverage and increase financial risk expected. As we know, either asset bubbles or financial risk, the real economy and the virtual economy are unstable factors, especially the asset bubble will lead to a false prosperity, its essence is serious damage to the social and economic structure, it is necessary to timely and effective leverage, anti foam. In order to achieve the goal of deleveraging, anti foam. The central bank requires the creation of an appropriate monetary policy environment, to prevent further imbalance in the economic structure, the weakening of basis risk arising from the accumulation of risk, the gradual release of the central bank's recent monetary energy. Market operation, is to prevent money off the real to the imaginary, with money speculation money and leverage is not reasonable, at the same time through the bond market arbitrage squeeze to raise speculation cost, to ease and avoid the risk of the bond market accumulation. Further, the central bank through adjustment and new initiatives on monetary policy, can effectively strengthen the real estate market control measures, to further overweight effect on the real estate market regulation, to eliminate and leverage its unreasonable, making the real estate regulation measures from the national day last year since the introduction of the hot city to further implement from the policy level, to avoid causing further damage to the social and economic structure.

\section{Prediction and Analysis of the Impact of Monetary Policy Adjustment on the Real Estate Market}

Monetary policy adjustments will be more conducive to the regulation of the property market. This time the central bank to adjust monetary policy, is actually to the commercial bank to release a clear signal, that is to strictly control new loans. Therefore, predictably, the first quarter of 2017 of RMB loans is expected to decline, this also means that the implementation will impact on China's economy in many industries have this a policy, especially for the real estate industry.

In the two or three quarter of 2016, China's real estate market had a shocking bull market, some hot city residents even doubled situation caused a strong growth in real estate credit. In October, the central bank issued a series of macro-control measures in a timely manner, but even in this case, prices are still strong contrarian rise.

Table 1 National loans increased in 2016(currency: RMB; unit: trillion)

\begin{tabular}{|c|c|c|c|c|}
\hline quarters & 1st quarter & 2nd quarter & 3rd quarter & 4th quarter \\
\hline New loan & 4.60 & 2.93 & 2.63 & 2.63 \\
\hline New housing loans & 1.20 & 1.75 & 1.77 & 1.77 \\
\hline Housing loan ratio & $26 \%$ & $60 \%$ & $67 \%$ & $67 \%$ \\
\hline
\end{tabular}

It can be inferred from the table, made a major contribution to the real estate market bull market for GDP in 2016, is still mainly rely on the real estate market to support. While the supply side reform, adjust the structure and increase the capacity to bring the profits of state-owned enterprises, the role is still only secondary[7-9].

In general, because we still is the implementation of loan management system, in order to avoid credit policy adjustments, banks are generally willing to advance lending, and enterprises are willing to get loans in advance, so the amount of credit is often in the first quarter is relatively high. So the first quarter of 2017, if household loans accounted for more than $60 \%$ still then, the size of loans will reach 2 trillion, this frenzy will be similar to the third quarter of 2016, and this is the central bank is not willing to see. So, the central bank released the regulation of strong signal, trying to stabilize the real estate market development in the controllable range, which can pierce the bubble, and not make the any bubble soaring. Thus, a social credit demand is very strong, the bank share of resources is more and more intense impulse; on the other hand, in order to control the real estate market, the central bank to bank 
credit It decreased, which resulted in faster credit the central bank regulation and deliberately suppressed speed of contradictions and conflicts. Therefore, the central bank through liquidity control to control the credit scale policy naturally appeared. Therefore, the central bank introduced a policy to control the reasonable mortgage growth is logical.

Prediction of the Real Estate Market Trend of the New Policy. At present, although China's economy has stabilized, but still a lot of uncertain factors, so many local governments lowered expectations of economic growth throughout the year. But the bank's credit structure has not changed significantly due to excessive credit growth, the central bank has issued a clear signal for commercial banks to strictly control the new loans. The adjustment of monetary policy is that the credit market in 2017 the wind will change, the impact on the real estate market will be enormous.

The following table is the central bank in recent years, the total amount of RMB loans, from the table can be seen, the total amount of loans increased year by year, the growth rate is faster and large.

Table 2 In the past six years, the new RMB loans (currency: RMB; unit: RMB)

\begin{tabular}{|c|c|c|c|c|c|c|}
\hline years & 2011 & 2012 & 2013 & 2014 & 2015 & 2016 \\
\hline Amount of money & 7.47 & 8.20 & 8.89 & 9.78 & 11.72 & 12.65 \\
\hline
\end{tabular}

The Central Bank's Monetary Policy Initiatives Will Further Strengthen the Effectiveness of the Real Estate Regulatory Policy. According to the table, from the statistical data in recent years, the scale of commercial bank loans in the first quarter, every year is an important period of commercial bank loans issued in the same period. The proportion of the total annual loan total loans in the quite high. Which is due to the commercial the bank in order to occupy the market, to seize the high-quality customers, achieve maximum benefit, but also to the financial risk averse central bank policy changes brought about. But the statistics also show that in the financial institutions issuing new loans, real estate loans accounted for the proportion is quite high[8,9].

Table 3 Commercial banks to add new loans quarterly distribution table (currency: RMB; unit: trillion)

\begin{tabular}{|c|c|c|c|c|c|}
\hline \multirow{4}{*}{2011} & 1st quarter & 2.14 & \multirow{4}{*}{2014} & 1st quarter & 3.01 \\
\hline & 2nd quarter & 1.93 & & 2nd quarter & 2.73 \\
\hline & 3rd quarter & 1.51 & & 3rd quarter & 1.94 \\
\hline & 4th quarter & 1.79 & & 4th quarter & 2.1 \\
\hline \multirow{4}{*}{2012} & 1st quarter & 2.46 & \multirow{4}{*}{2015} & 1 st quarter & 3.68 \\
\hline & 2nd quarter & 2.4 & & 2nd quarter & 2.88 \\
\hline & 3rd quarter & 1.86 & & 3rd quarter & 3.34 \\
\hline & 4th quarter & 1.48 & & 4th quarter & 1.82 \\
\hline \multirow{4}{*}{2013} & 1st quarter & 20.76 & \multirow{4}{*}{2016} & 1st quarter & 4.61 \\
\hline & 2nd quarter & 2.82 & & 2nd quarter & 2.92 \\
\hline & 3rd quarter & 2.2 & & 3rd quarter & 2.63 \\
\hline & 4th quarter & 1.61 & & 4th quarter & 2.49 \\
\hline
\end{tabular}

So this kind of behavior will affect the commercial bank the stable development of the real estate market, caused the ups and downs. The adjustment of monetary policy of the central bank, is the financial institutions in order to suppress the love at the beginning of water while the impact of the real estate regulation effect a A normal right move. Through this initiative, the central bank can guide, control and regulate the amount of new loans in the first quarter, the release of the entire real estate loans or the tightening signal, further strengthen the real estate regulation measures, so that the real estate regulation tightening policy to implement. 
Macro-Control of Real Estate under the Conditions of the Growth Rate of Loans Will Be Subject to Restrictions and Limitations of Monetary Policy. The following table lists detailed new in recent years, real estate loans accounted for the proportion of total new loans, we can see from the table, in the amount of new loans for the new real estate loans to the irrational proportion, and the proportion of showing a growing imbalance trend, from $9.8 \%$ in 2012 soared to at present, 54\%. can be said to be in a crazy state of rapid growth, this point in 2016 performance is very prominent.

From the table we can also see that each quarter year-on-year growth of real estate loans have greatly increased, if in accordance with this growth calculation, can be expected in 2017 each quarter for new real estate loan amount will reach 2 trillion. But obviously with the central bank's control target is inconsistent, because the central bank target has made it clear that in 2017 the first quarter real estate loan growth and amount to less than a quarter, the credit growth too fast than financial institutions may be affected by the deposit reserve rate penalty. Based on the above analysis and prediction, compared with 2016, the first quarter of 2017, the new real estate loans will decline greatly in the past, in order to avoid the situation in the year, which will have a huge role in the regulation of the real estate market, so as to ensure the stable development of the real estate market.

Table 4 Real estate loans accounted for the proportion of total loans distribution table (unit: \%)

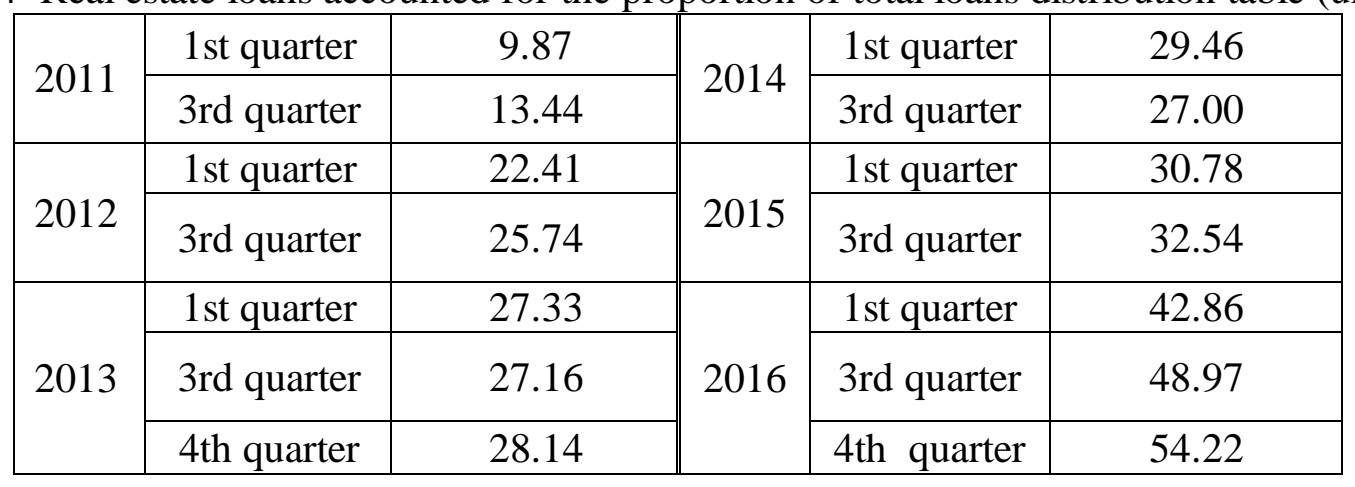

New Monetary Policy Initiatives will Reduce the Total Amount of New Real Estate Loans, Lower Growth. From the historical data we can see that the central bank to adjust monetary policy, its purpose is to compress new loans, and the impact of this policy, the first is the real estate industry. Therefore, the 2017 year and reduce the credit due to the impact of monetary policy, coupled with the hot state of the city's purchase of the policy, two pronged, comprehensive regulation, efforts can be said is hitherto unknown. Therefore, there is no doubt that 2017 prices will return to rational, and is expected to fall.

To sum up, the real estate market in 2017, will have a smooth and slightly Yindie trend. Because in recent decades of development of the real estate market bubble will increase again, is absolutely not allowed. For each hot city, but also by various means and measures continuously, to control prices. At the same time, the current deposit and loan interest rates are relatively low, liquidity is relatively loose, so it is difficult to appear. But prices fell from the beginning of the second quarter, is expected to have a considerable part of the city's housing prices will fluctuate, showing a downward trend. Then just group, improve needs of the group is the purchase of a good time. The hot city as the population and the incremental funds are larger, the quality of residential long-term investment value is obvious, but the three or four line of the city, will be very difficult to pick up.

\section{Conclusion}

In recent years, the global economy is facing many uncertain factors, China in 2017, both from the economic or from the financial point of view is full of uncertainty, but the orientation from the occasion of the 2017 monetary policy, has released a very clear signal, that is to continue to robust, stable economic and financial order. But monetary policy should be specific what measures to deal with the 
uncertainty, so that the trend of economic and financial stability? Whether it is from the international level or from the domestic perspective, to deal with the uncertainty, is facing great challenges.

From the central bank's authoritative statement can be seen in 2017, prudent monetary policy will be more neutral, but also will be more cautious. This means that the central bank will further adjust the monetary floodgates, the integrated use of quantity and price of tools and macro Prudential policy, to strengthen pre and fine-tuning to actively respond to the perplexing domestic and international economic and financial situation therefore, predictably, expected 2017 monetary policy will promote structural adjustment, anti foam, steady growth, balanced development of the relationship between the anti risk.

At present, domestic and international political, economic and financial situation is at a very critical period, from an international perspective, the international big financial institutions have forecast, the Fed will continuously raise interest rates, but the Fed rate hike in the operation is quite cautious. In China, although the economy of our country has been the steady rise, but the rebound is facing many uncertainties, the need to further consolidate, adjust the structure of steady growth still needs further force, the RMB exchange rate is still under a lot of pressure. In this situation, monetary policy must undertake many tasks at the same time, taking into account all aspects of the relationship the development, balance and coordination of all aspects, it is necessary to create a suitable environment for supply side reforms, but also take into account the structural adjustment and steady growth, therefore, monetary policy has been restricted in many ways, the slightest mistake, it Will the imbalance relationship, as the direction of China's economic impact. The face involves many constraints, any monetary policy even fine-tuning, all need to be careful, to coordinate the relationship in many aspects with superb skills and arts.

The central economic work conference, pointed out the direction for the 2017 economic development direction and the goal, the central bank's monetary policy will focus on the goal of operation. Predictably, this operation must be taken in order, progressive ideas, to maintain the overall steady state, both impact on financial markets and the real economy, at the same time with the economic situation, according to the domestic financial market reaction, and the real economy trend, through careful operation in real time on the policy to make dynamic adjustment. At the same time, our monetary policy will also pay close attention to changes in the international financial and economic situation, including the Fed interest rate process and the fluctuation of RMB exchange rate, so this adjustment will be modest and cautious.

With the rapid development of China's economy in recent decades, China has risen as the world's second largest economy, economic scale is very large, the mutual influence and interaction of all walks of life have become increasingly close, at the same time, along with our country more and more deeply into the world economic system, and the influence of economic globalization on me in China more and more deeply, a new monetary policy framework has been gradually formed. This means that the central bank is not only concerned about short-term economic policy changes, the construction also focus on the long-term mechanism, in this new monetary policy framework, the central bank can make the appropriate pre change according to the situation of economic development and fine-tuning.

From the development trend in recent years, monetary policy can be seen in the type of regulation and control of monetary policy in China has been undergoing subtle changes, the implementation of the past our monetary policy is more regulation in the number of type, and now we will pay more attention to the regulatory role of the market interest rate, which is the implementation of that monetary policy is to price regulation transformation. This will further promote the interest rate market, the interest rate adjustment to rely more on the market, and this will bring the deepening of financial reform, the market benchmark interest rates and the yield curve is more complete and consistent with the economic situation changes, the future direction of monetary policy will be more robust, the mechanism will be more perfect. In a word, one has been integrated into the world economic giant, is forming a market oriented interest rate changes, and guide financial institutions Rational economic investment, risk prevention, full of vitality, more robust and perfect mechanism. 


\section{Acknowledgements}

This work is supported by the Ph.D. Foundation of Henan University of Engineering (No. D2010012).

\section{References}

[1] M.H Shao,.2017 Shanghai property market outlook [J]. Shanghai real estate. 2017 (01)

[2] W.Z Wang, Thinking of the cold and hot of the real estate market in China [J]. Guangdong economy. 2017 (03).

[3] G.Y Li, Z.Y Zhang, The impact of the central bank's interest rate hike on the demand for real estate [J]. Economic Forum. 2017 (01) Zhang Bizhou van.

[4] F Hang, A new analysis of factors affecting the real estate market and expand the personal loan business of commercial bank [J]. Financial science. 2016 (11).

[5] Y Zhi, Information helps the real estate market regulation [J]. China Construction information. 2016 (21).

[6] R.H Wang, The high leverage risk of the property market had to prevent [J]. Urban development. 2016 (24).

[7] X.Y Wu, Y.J Chen, Reflections on the regulatory mechanism of the real estate market [J]. Business managers. 2016 (06).

[8] X.H Xu, Analysis of the impact of central bank interest rate hikes on China's real estate market [J]. Inner Mongolia science and technology and economy. 2016 (22).

[9] Y.T Wang, Research [J]. Jiangxi building materials regulation between land supply and real estate market. 2016 (19). 